\title{
PROCESOS DE CONFIGURACIÓN TERRITORIAL Y CONFLICTOS POR EL AGUA EN EL MUNICIPIO DE PASTO, COLOMBIA
}

\author{
Jorge Andrés Perugache Salas*
}

\section{RESUMEN}

El propósito de este artículo, es analizar los conflictos sociales, políticos y ambientales por el acceso y distribución del agua en los andes suroccidentales de Colombia, específicamente en el municipio de Pasto. A partir del análisis de dos momentos históricos y haciendo uso de una perspectiva etnográfica, muestra cómo las élites políticas y económicas en el municipio, han tenido una posición hegemónica en la definición de los derechos para el acceso al agua, favoreciendo la acumulación y flujo de capital, excluyendo formas de apropiación, uso y distribución del líquido que responden a intereses colectivos, relacionados a la defensa de la autonomía territorial y la legitimación de identidades comunitarias. Esto ha confluido en escenarios de tensiones, que han involucrado pobladores rurales y urbanos, instituciones estatales, gremios económicos y productivos, entre otros.

Palabras clave: acueductos comunitarios, agua, conflictos socioambientales, infraestructura hidráulica, territorio, relaciones urbano-rurales.

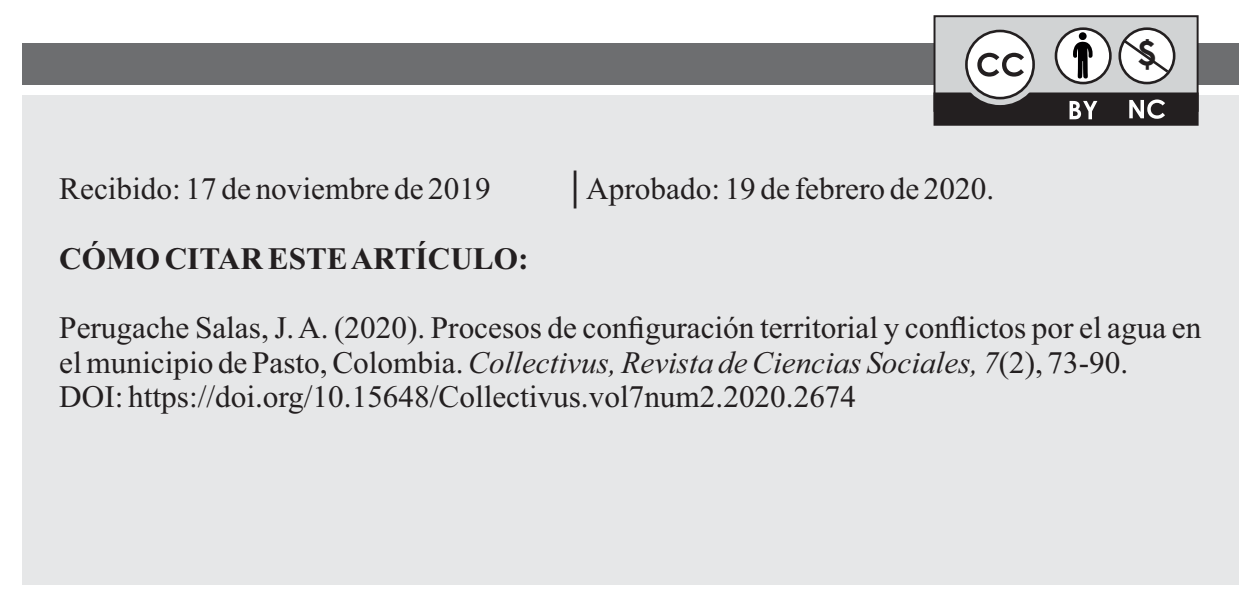

\footnotetext{
"Magíster en Antropología. Doctorando en Antropología de la Universidad Nacional Autónoma de México e investigador del Instituto Andino de Artes Populares de la Universidad de Nariño. Bloque Facultad de Educación, sede VIPRI, Universidad de Nariño, Pasto, Colombia. Correo electrónico: andresperugache@gmail.com.
} 
74| Procesos de configuración territorial y conflictos por el agua en el Municipio de Pasto, Colombia

\title{
TERRITORIAL CONFIGURATION PROCESSES AND WATER CONFLICT IN THE MUNICIPALITY OF PASTO, COLOMBIA
}

\begin{abstract}
The purpose of this article is to analyze the social, political and environmental conflicts over the access and distribution of water in the southwestern Andes of Colombia, specifically in the municipality of Pasto. From the analysis of two historical moments and making use of an ethnographic perspective, it shows how the political and economic elites in the municipality have had a hegemonic position in the definition of rights for access to water, favoring the accumulation and flow of capital, excluding forms of appropriation, use and distribution of the liquid that respond to collective interests, related to the defense of territorial autonomy and the legitimation of community identities. This has come together in scenarios of tension, which have involved rural and urban residents, state institutions, economic and productive unions, among others.

Keywords: community aqueducts, hydraulic infrastructure, socio-environmental conflicts, territory, urban-rural relations, water.
\end{abstract}

\section{Introducción}

Es importante dar a conocer los avances de esta investigación, la cual estudia las transformaciones en las formas de manejo y uso del agua y su relación con procesos de configuración territorial, en un contexto de relaciones urbano-rurales profundamente desiguales y racializadas. Este texto, se inscribe en las discusiones y el interés de la ecología política a propósito de los elementos sociales, políticos, económicos y culturales que atraviesan la relación entre sociedad y naturaleza. De manera concreta, parte de dos consideraciones: la primera, entender que el manejo y uso del agua está atravesado por relaciones de poder, donde intervienen intereses políticos, económicos y significados culturales sobre este elemento en particular y la naturaleza, en general. La segunda, guiada por la idea de coproducción de la sociedad y la naturaleza. Sostiene que el agua no solamente es un agente pasivo sobre el que recaen acciones e intereses, sino que su materialidad influye y moldea relaciones sociales y políticas, acentuando o limitando relaciones de poder.

Teniendo en cuenta lo anterior, en este trabajo se retoma el concepto de territorio hidrosocial, con el fin de problematizar la relación entre agua y territorio y las disputas que surgen, como resultado de la superposición de distintos significados en torno a estos elementos. Entendidos como "espacios constituidos social, natural y políticamente que son (re)creados mediante las interacciones entre las prácticas humanas, los flujos de agua, las tecnologías hidráulicas, los elementos biofísicos, las estructuras socioeconómicas y las instituciones político-culturales" (Boelens et al., 2017, p.85), los territorios hidrosociales suponen entender el territorio, no solamente como una forma de apropiación económica y cultural del espacio, sino como un escenario donde se producen y reproducen las relaciones de poder en torno al agua. 
Una manera de entender los procesos de configuración de los territorios hidrosociales, así como su disputa es a través de la infraestructura hidráulica. Esta se entiende aquí, como una producción sociotécnica que encarna significados e imaginarios en relación con el agua, y tiene un papel determinante en la definición de quiénes se benefician y quiénes son excluidos en el acceso al líquido (Boelens etal., 2017; Swyngedouw, 2009). En este sentido, la infraestructura hidráulica es un campo etnográfico, privilegiado para observar las luchas por el control del agua tanto en el nivel material como simbólico, así como la configuración de ordenamientos territoriales desiguales.

Abordando las investigaciones de Marcela López (2016), y de Radonic y KellyRichards (2015), en los contextos colombiano y mexicano, respectivamente, este trabajo se acerca a los arreglos locales para el acceso al agua, que, a través de prácticas cotidianas e infraestructuras, son puestas en práctica por parte de sectores sociales, perjudicados por la distribución desigual de este elemento en contextos urbanos y urbano-rurales. En concreto, intentan comprender los sistemas locales para el manejo del agua y sus transformaciones, y los conflictos y tensiones que emergen por la apropiación, uso y distribución del agua en el municipio de Pasto, en el suroccidente andino colombiano. Para la elaboración de este proyecto, se tuvo en cuenta la revisión de archivos documentales del Archivo Histórico de Pasto y la realización de un trabajo de campo etnográfico intensivo. La investigación, ha estado guiada por una perspectiva de investigación-acción solidaria, tendiente a la construcción colectiva de conocimientos con los sujetos de estudio, mediante el uso de metodologías de carácter participativo y el compromiso social del investigador. ${ }^{1}$

\section{El valle de Atriz, una historia trazada por el agua}

El valle de Atriz, donde está asentada la ciudad de Pasto, está ubicado en las estribaciones orientales del volcán Galeras, en el Nudo de los Pastos o Nudo de Huaca, en los andes suroccidentales de Colombia. Históricamente, esta región ha sido el escenario de encuentros de diversos grupos humanos. Desde la fundación hispánica de la ciudad, en la parte baja del valle en 1539, han confluido allí poblaciones de origen europeo, mestizos y pobladores nativos. Sin embargo, estos últimos, han sido desplazados y confinados a la parte alta del valle, congregados en resguardos ${ }^{2}$ indígenas desde la época colonial hasta mediados del siglo XX, y posteriormente integrados y sujetos administrativamente como corregimientos y veredas rurales, como áreas suburbanas y barrios del municipio de Pasto.

La relación entre los habitantes de la ciudad y los de sus alrededores, son de larga data y no dejan de tener un carácter ambiguo, debido a la mutua dependencia de Pasto por las tierras y recursos de la parte alta del valle de Atriz y de la fuerza de trabajo indígena y campesina, y también, de la dependencia económica de estos últimos de la ciudad. Actualmente, las familias que están conformadas por las, aproximadamente, setenta y

\footnotetext{
${ }^{1}$ Algunos antecedentes de esta perspectiva metodológica pueden encontrarse en la obra y pensamiento de Orlando Fals Borda. Al respecto, ver el trabajo de Suárez (2020), en el número 1 del volumen 7 de Collectivus, Revista de Ciencias Sociales.

${ }^{2}$ El resguardo, fue una institución española de origen colonial instaurada en algunas regiones de América con la doble finalidad de proteger a la población nativa que venía disminuyendo drásticamente.
} 
cuatro mil personas que viven en el área rural del municipio de Pasto, cuya población total es de cuatrocientos mil habitantes, mezclan las actividades que llevan a cabo en la ciudad con la agricultura, la cría de animales y la elaboración de productos artesanales.

En el contexto geográfico del valle de Atriz, el agua ha sido un elemento central en la apropiación y uso del territorio y la definición de las relaciones de quienes allí habitan. El favorecimiento de algunos sectores, casi siempre de quienes han habitado la parte baja, ha significado el perjuicio de quienes han sido empujados progresivamente hacia la parte alta del valle. Sin embargo, como se verá a continuación, los procesos de configuración territorial, en general, y de uso y apropiación del agua, en particular, han sido una lucha de tensiones y conflictos permanentes. Para ejemplificar esto, este artículo se detiene en dos momentos, en los cuales se intensificaron las disputas por el acceso y distribución del agua en el valle de Atriz y los cuales representaron cambios significativos a nivel social y político para las comunidades rurales que rodean la ciudad de Pasto.

El primero abarca las décadas comprendidas entre los años 1930 y 1950 . Durante este período Pasto creció de manera notable a raíz de la apertura de la carretera que la comunica con el norte del país, lo que llevó a la liquidación de los resguardos que rodeaban a la ciudad y la agudización de los conflictos por la tierra y por el agua. El otro período, abarca desde finales de la década del año 2000 hasta el presente. Este se ha caracterizado por un crecimiento urbano sin precedentes, lo que, sumado a otros fenómenos, ha incidido de manera notable en el aumento de los intereses y disputas por el agua, impactando los territorios de las poblaciones rurales del municipio de Pasto.

\section{Haciendas y resguardos en el valle de Atriz}

El período comprendido entre las décadas de 1930 a 1950, se caracterizó por el apogeo de comercios y pequeñas manufacturas en Pasto, tales como panaderías, aserríos, tejerías, curtiembres y tenerías. Esto ocurrió, gracias a la apertura de la carretera que unió a la región con el resto del país, construida a raíz del conflicto colombo-peruano de 1932. La nueva vía, también favoreció la exportación de productos agrícolas a otros departamentos, incidiendo considerablemente en su producción, así como el crecimiento de la población de Pasto, por la migración proveniente de otras regiones del departamento.

Lo anterior afectó de manera notable la configuración territorial del valle de Atriz, incidiendo en la ampliación de latifundios para la producción agrícola y la reducción de los resguardos indígenas de la parte alta. El interés por las tierras comunales aumentó de manera considerable, porque de allí se extraían recursos como la madera y carbón vegetal para el funcionamiento de los hornos de las panaderías, así como materiales para la construcción, tales como gravas, piedra y arena.

Como consecuencia de la falta de tierra por la sobrepoblación en sus comunidades y el despojo territorial que venían sufriendo desde la época colonial, las comunidades indígenas del valle de Atriz debieron desplazarse hacia las laderas boscosas, migrar a la ciudad o apegarse a las haciendas bajo condiciones serviles. Estos hechos, agravaron los conflictos internos dentro de las comunidades y condujeron a la liquidación de los resguardos indígenas. Con el fin de obviar el largo y costoso trámite que significaba la repartición de las tierras comunales, el Estado colombiano desconoció la existencia de los títulos coloniales y republicanos, declarando estas tierras como baldías y a sus ocupantes como colonos en suelos de la nación. Este proceso culminó en 1950. 


\subsection{Agua y modernización en Pasto}

Durante este período el crecimiento de Pasto, así como el apogeo manufacturero, agrícola y comercial, llevó a la modernización de la infraestructura urbana que tuvo al agua como un componente esencial.

Hasta mediados de la década de 1930, las aguas residuales domésticas y las aguas lluvias de la ciudad, se descargaban en las acequias que bajaban por las principales calles y el agua para consumo, se recogía en pilas distribuidas en varios sectores. Sin embargo, los problemas de higiene derivados de esta situación, sumado al interés estatal por la salubridad pública y los discursos modernistas de la época, resultado de la naciente República Liberal que sucedió décadas de hegemonía conservadora en Colombia, condujeron a una progresiva presión por parte de las élites locales quienes solicitaron al gobierno central, recursos para la construcción del sistema de acueducto y alcantarillado a lo largo de la década de 1930. Estas reclamaciones, que se replicaron en varios puntos del país, condujeron al gobierno de la época a la promulgación de la Campaña de Cultura Aldeana, la cual se propuso transformar la mentalidad popular, mediante la introducción de prácticas modernas (Álvarez, 2012, p.215) y la expedición de una serie de normas, en particular las leyes 65 y 109 de 1936, dirigidas a garantizar la inversión estatal en los servicios públicos de las ciudades, terminando con el monopolio que las empresas privadas tenían desde 1875, para el suministro de agua, a través de concesiones otorgadas por el Estado (Quintana, 2008).

Sin embargo, para el caso del municipio de Pasto, la idea de un acceso público y universal al agua tuvo varios atenuantes. Por una parte, el naciente proyecto de acueducto se proyectó solo para algunos sectores de la ciudad por lo que los habitantes de "barrios obreros" reclamaron mediante oficios y solicitudes a la alcaldía por su conexión a la nueva red de acueducto. Por otra parte, la canalización del río Pasto, cuyas aguas fueron utilizadas para el acueducto, afectó a quienes vivían en la parte alta de la cuenca, donde estaban asentadas las parcialidades indígenas de La Laguna y Buesaquillo. La preocupación de la alcaldía de Pasto por el abastecimiento de agua en la ciudad, condujo a un mayor control sobre las cuencas por parte de funcionarios de esta entidad, influyendo en el manejo que las comunidades indígenas hacían del agua y sus tierras.

De igual manera, el carácter público en la prestación del servicio de acueducto para algunos sectores de Pasto, contrastó con el hecho de que algunos dueños de haciendas, que tenían sus tierras en los límites de la ciudad y los resguardos, entorpecieran el abastecimiento de agua y los sistemas que los indígenas utilizaban para tal fin. Esto dio lugar a disputas que se dirimieron a través de largos procesos judiciales, al cabo de los cuales quienes resultaban favorecidos, generalmente, fueron los hacendados, quienes a su vez tenían vínculos políticos e incluso familiares con funcionarios de la alcaldía y los despachos judiciales. Para ejemplificar esto, se mostrará un caso que involucró a las parcialidades indígenas de Puerres, Canchala y Mocondino y los propietarios de la hacienda El Tejar, en el sector suroriental del valle de Atriz.

\subsection{Acequias, chorros y pocetas}

Los habitantes de Mocondino, Puerres y Canchala, se abastecían del agua que provenía del páramo y descendía por una caída de agua conocida hasta la actualidad como La Toma, a través de un sistema de acequias, pilas y chorros. El agua se encausaba a través de una acequia general, que servía a los tres pueblos y cuya limpieza se hacía periódicamente por medio de mingas, un sistema de trabajo comunitario andino de origen 
prehispánico. De la acequia, salían pequeñas derivaciones que llevaban el agua a varias viviendas. Las familias construían chorros, construcciones rudimentarias hechas con piedras y tejas, para la recolección del líquido los cuales eran compartidos por entre tres y cuatro casas.

Además de las discrepancias frecuentes, como la contaminación del agua cuando se lavaba ropa, los conflictos más acuciantes por el uso del agua en estas poblaciones involucraron a sus cabildos ${ }^{3}$ y los dueños de las haciendas ubicadas en la parte baja del valle. Estos casos, implicaron a varios miembros de la familia De la Rosa, propietarios de extensos latifundios dedicados a la cría de ganado, que lindaban con los resguardos indígenas de Puerres, Canchala y Mocondino. Uno de estos episodios tuvo lugar en 1939, cuando Carmela De la Rosa de Gavilanes, mediante su apoderado y hermano Luis Ignacio De la Rosa, elevó una queja ante la alcaldía de Pasto, por la obstaculización de un cauce de agua artificial que corría hacia sus propiedades en la hacienda El Tejar.

En junio de 1940, el alcalde de Pasto Alberto Ricaurte, esposo de la sobrina de la querellante, impuso una multa a los cabildos de Puerres, Mocondino y Canchala debido a la obstrucción del cauce artificial. En 1941, José Velasco y Leónidas Puerres, cabildantes de Canchala y Puerres respectivamente, además de apelar la multa impuesta por la alcaldía, denunciaron la grave situación que afrontaban por la falta de agua ocasionada por la desviación artificial que todavía mantenía la señora Carmela De la Rosa de Gavilanes:

(...) cuando la señora de Gavilanes quiere llevar las aguas a su fundo, es entonces cuando llegan a ver las personas afectadas, con ese hecho, el mal que se les causa y para atender a sus necesidades -EL AGUA ES UNA NECESIDAD ESENCIAL- es entonces cuando se disponen a hacerse respetar y efectivamente quitan todo obstáculo que a la corriente se ponga, ya sea natural o artificial, ya sea de barro o de cal y ladrillo. Es lo que se llama limpieza del cauce. La poceta en referencia o el obstáculo a la corriente, como lo llamamos nosotros no alcanzó a permanecer ni diez días, porque no podía convenirse el hecho injustificado de entregar hasta el agua a personas que no la han tenido nunca, que no tienen necesidad ni menos derecho a ella. (f. 269r).

En general, en los expedientes judiciales de todos los procesos que enfrentaron a propietarios de haciendas e indígenas, se aprecia como progresivamente, a la par del crecimiento urbano, de los latifundios, de la reducción de los resguardos y su sobrepoblación, aumentaron los intereses por las aguas que bajaban de la parte alta del valle de Atriz. Es sugerente ver cómo estos intereses pueden materializarse en la infraestructura construida para el manejo del agua, lo cual a su vez incide en el beneficio de ciertos sectores y el perjuicio de otros.

Por una parte, la red de acueducto de la ciudad afectó el manejo del agua que los indígenas hacían en la parte alta de la cuenca, además la red construida benefició solamente a algunos barrios de Pasto, donde se encontraban sectores con los más altos ingresos. Por otra parte, a propósito de las confrontaciones entre indígenas y hacendados, la infraestructura hidráulica refleja los intereses y visiones en torno al manejo del agua. Para los hacendados, el agua era un bien privado susceptible de ser acaparado, para lo cual construían pocetas y cauces artificiales con el fin de retener el líquido. Para los indígenas en cambio el agua era "una necesidad esencial" que satisfacía necesidades de carácter público, no exclusivamente para beneficio personal (Perugache, 2017, p.169). Por eso, a

\footnotetext{
${ }^{3}$ El cabildo indígena, fue un sistema de gobierno instaurado por el gobierno colonial español para el control interno de las comunidades nativas.
} 
raíz de la denuncia de Carmela de la Rosa de Gavilanes los indígenas, no concebían que el agua tuviera algún obstáculo y para ellos como algo natural y cotidiano, realizaban la limpieza de los cauces.

Durante las décadas de 1930 y 1940, los comuneros y cabildos enfrentaron con firmeza las acciones emprendidas contra ellos para impedir el uso del agua, participando activamente en los procesos judiciales o bien tomando acciones de hecho, como la limpieza de los obstáculos construidos para retener el agua. Sin embargo, estas acciones deben leerse en el marco de la lucha de las comunidades indígenas por mantener el control no solo sobre el agua, sino también sobre sus territorios.

\section{Acueductos comunitarios y conflictos por el agua en el valle de Atriz}

\subsection{La ficción de la ciudadanía}

Luego de la liquidación de los resguardos, la vida de los habitantes de la parte alta del valle de Atriz empeoró debido a la falta de tierra y el aumento de los minifundios, lo que obligó a un buen número de los antiguos comuneros a migrar a otras regiones de Colombia, como el Valle del Cauca, para trabajar en la agroindustria de la caña, al piedemonte amazónico y al Ecuador. Además, aunque dejaron de ser considerados como "menores de edad", que era el tratamiento que la ley les daba como indígenas, y haberse convertido en "ciudadanos con plenitud de derechos", los antiguos miembros de las parcialidades siguieron manteniendo una condición social de inferioridad. Esto se evidencia, por ejemplo, en la continuidad de obligaciones originadas en la época colonial, como el servicio obligatorio y gratuito que debían cumplir en la ciudad, en la limpieza y la construcción de calles, edificios e iglesias, a cambio del usufructo de sus resguardos.

El crecimiento de la ciudad fue absorbiendo paulatinamente los antiguos resguardos a partir de mediados de siglo. Los pueblos ubicados en el sector suroriental del valle de Atriz como Puerres, Canchala, Pejendino y Mocondino fueron afectados por los programas de vivienda popular, donde antiguamente estaban ubicadas las haciendas El Tejar y Mercedario desde 1958. Adicional a esto, la reactivación del volcán Galeras, ubicado en las estribaciones occidentales del valle de Atriz, a finales de la década de 1980, agudizó aún más la presión sobre el sector suroriental del municipio. Los barrios construidos a lo largo de la década de 1990, en este sector, forman actualmente un continuo urbano entre Pasto y las veredas Puerres y Canchala.

La historia de la creación de estos barrios, habitados en parte por pobladores provenientes de zonas rurales del departamento y de regiones cercanas como el Putumayo, golpeadas por la agudización del conflicto armado interno en Colombia desde finales de la década de 1990, fue de la mano de la construcción de redes e infraestructuras para el abastecimiento del agua y su manejo autogestionado a través de acueductos comunitarios. Actualmente, en el sector suroriental del municipio de Pasto, existen cinco acueductos de este tipo, que se abastecen de agua de la microcuenca de la quebrada Dolores, la misma que surte del líquido al acueducto del corregimiento de Mocondino, el cual está integrado por las veredas Dolores, Mocondino, Canchala y Puerres. Así, el sector suroriental del valle de Atriz, está caracterizado por la confluencia y entrecruzamiento de distintas redes hidráulicas y de "distintas aguas", la de EMPOPASTO, la empresa municipal de acueducto y alcantarillado, cuya red abarca solo los barrios ubicados en el perímetro de la ciudad, los acueductos comunitarios de los barrios suburbanos y del corregimiento de Mocondino (ver figuras 1 y 2). 
Figura 1. Sectorización hídrica del valle de Atriz y del corregimiento de Mocondino
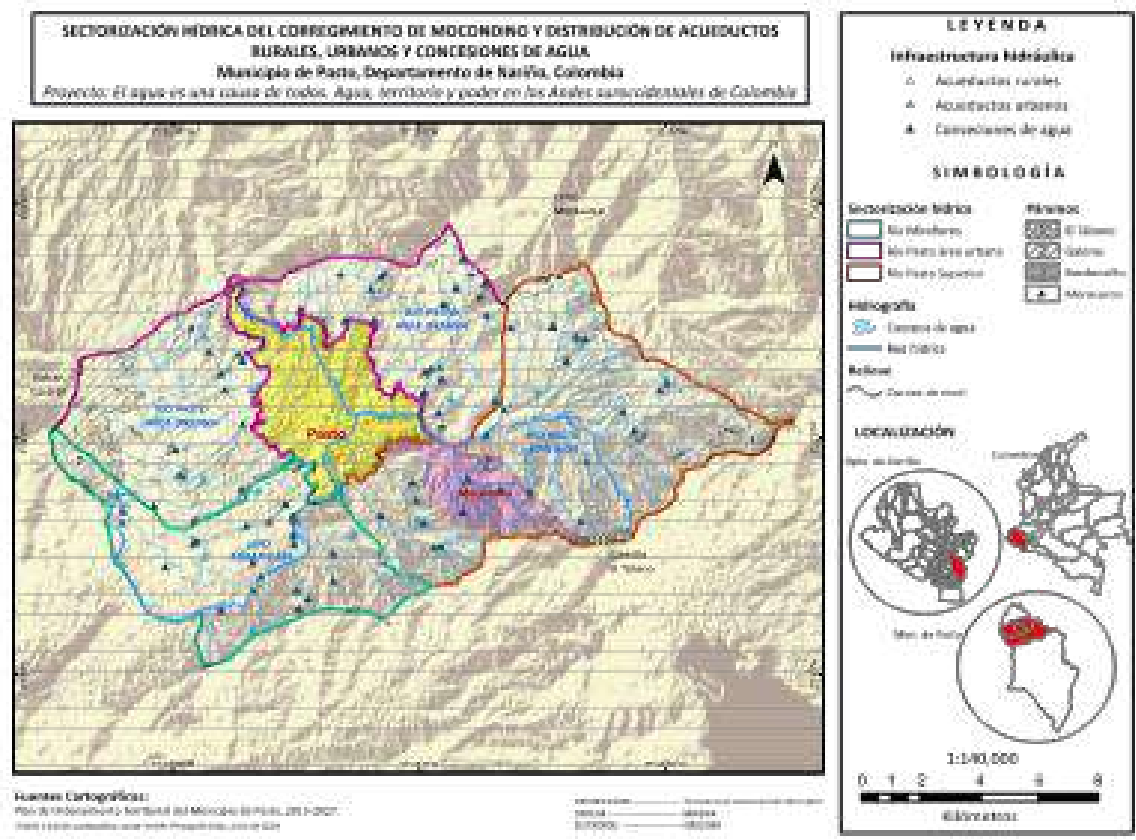

Fuente: presente investigación.

Figura 2. Uso y distribución del agua en el corregimiento de Mocondino

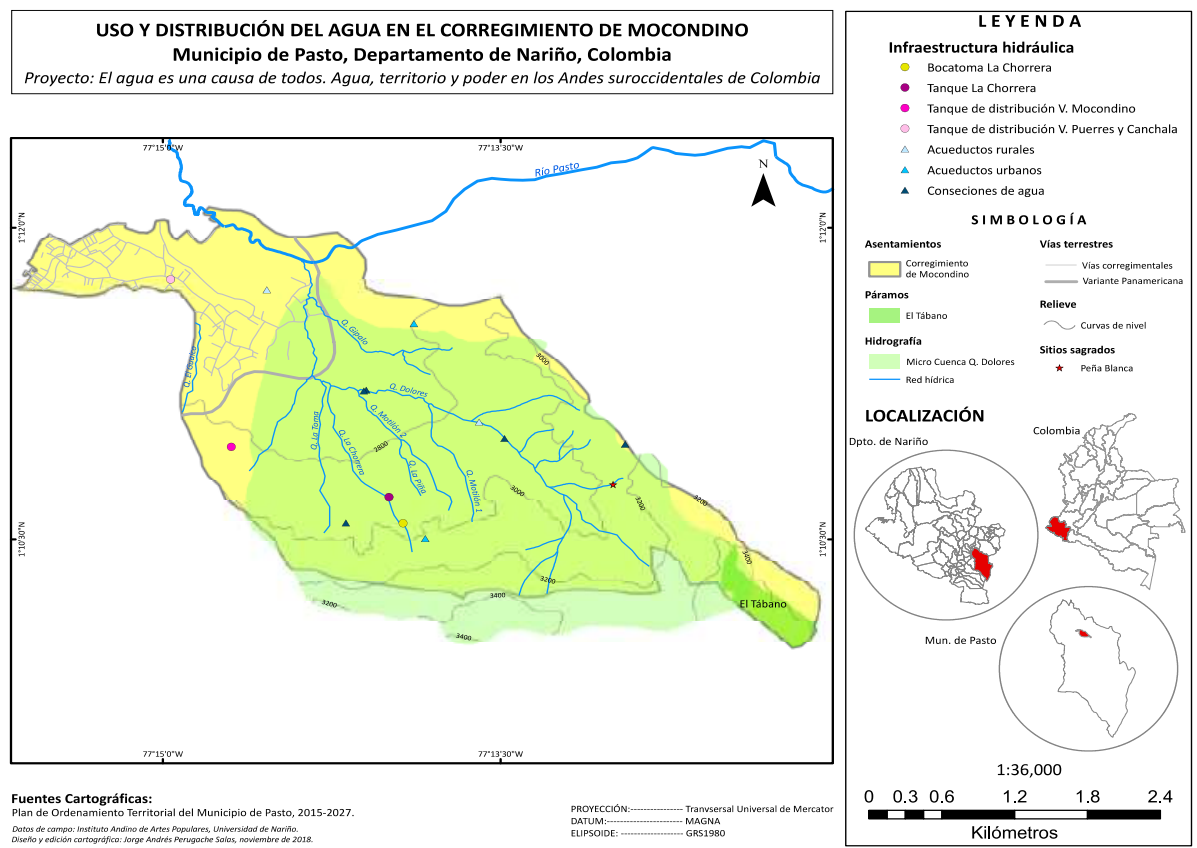

Fuente: presente investigación. 
Al panorama descrito anteriormente, se suman los intereses de empresas privadas por el agua de la microcuenca de la quebrada Dolores. A partir de la Ley 142 de 1994, se trasformó la prestación del servicio de agua en Colombia. El Estado, permitió que las empresas privadas entraran a competir en la provisión del agua y posibilitó su uso concesionado a particulares, al considerar al agua como un bien económico. La entrega de concesiones, fue delegada a las autoridades ambientales regionales (corporaciones autónomas regionales). En el caso del municipio de Pasto, la corporación autónoma regional, CORPONARIÑO, ha otorgado concesiones de agua a empresas dedicadas a la producción avícola y porcina de la microcuenca de la quebrada Dolores, establecidas en el corregimiento de Mocondino. Adicional a esto, esta misma institución renovó en años recientes una licencia ambiental a la cantera Calidad, ubicada a escasos cien metros de la orilla de esta quebrada, para la explotación de 80 hectáreas destinadas a la extracción de piedras y materiales de construcción, la cual no ha entrado en funcionamiento por la oposición de las juntas de los acueductos comunitarios de la zona.

\section{Figura 3. Área de explotación de la cantera Calidad}

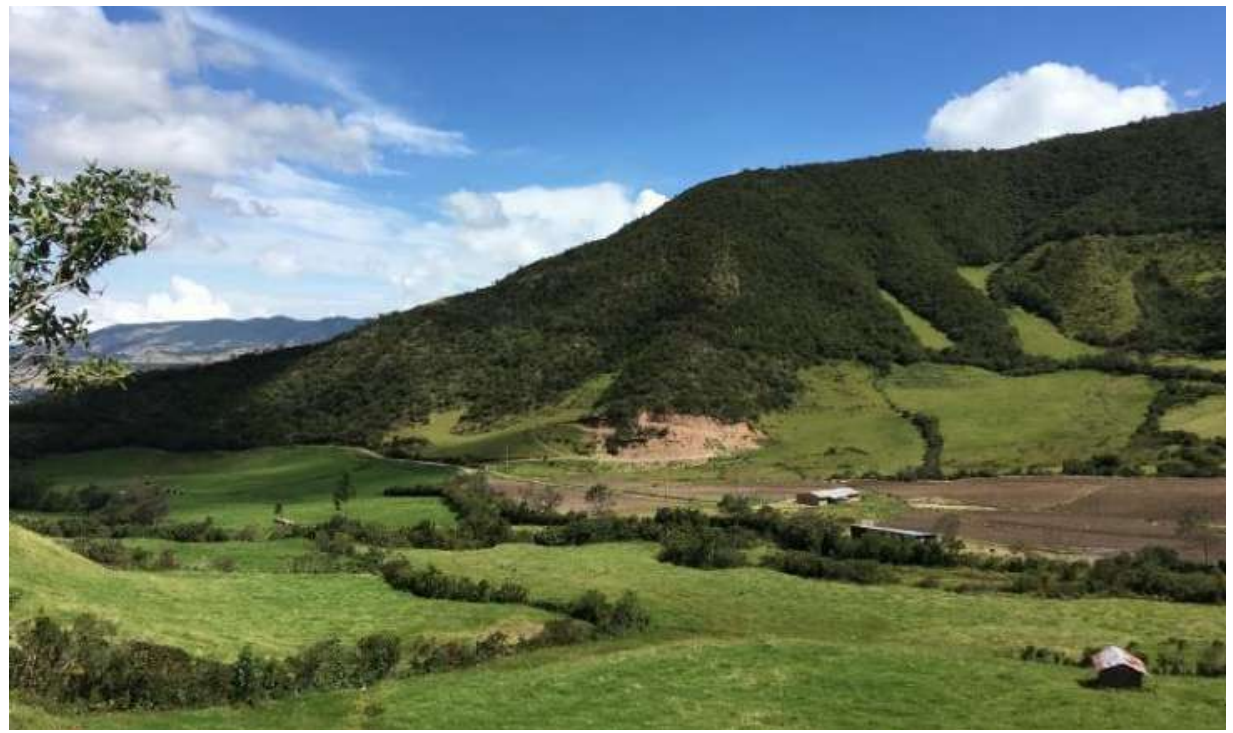

Fuente: presente investigación.

Este conjunto de actores y de hechos ha incidido en la agudización de los conflictos por el uso, manejo y apropiación del agua en el sector suroriental del municipio de Pasto. El crecimiento urbano no planificado hacia ese sector, sumado a los intereses de algunas empresas, ha ocasionado que los habitantes rurales de la zona, hayan denunciado en diferentes oportunidades la falta de agua en sus hogares, particularmente en épocas secas. Si bien, esta situación se ha agudizado por el crecimiento de la población interna de las veredas, también es cierto que la sobredimensión de caudales y el aumento en las concesiones de agua, para fines agroindustriales ha tenido un efecto considerable sobre este fenómeno. A lo anterior se suman los proyectos para el loteo y construcción de viviendas en Mocondino, que contrariando las normas establecidas en el Plan de Ordenamiento Territorial que prohíben la urbanización de las zonas rurales del municipio, han sido el detonante de un largo conflicto, que ha involucrado a urbanizadores, entidades municipales y a los pobladores de Mocondino, Puerres y Canchala. 
$\mathbf{8 2}$ Procesos de configuración territorial y conflictos por el agua en el Municipio de Pasto, Colombia

Antes de hacer referencia a este caso, se mencionan algunos aspectos sobre la trasformación del sistema de abastecimiento de agua en Mocondino, y las disputas actuales en torno al manejo comunitario del líquido a nivel local, regional y nacional.

4.2. Del agua del chorro al agua de la llave

En el valle de Atriz, la disolución de los resguardos indígenas y del régimen de propiedad comunal antes de 1950, supuso la desaparición de los cabildos indígenas, que funcionaban como autoridades propias regidas por usos y costumbres. Sin embargo, la desintegración territorial y social de estas comunidades fue atenuada por varios factores, entre ellos, el hecho de que la propiedad de la tierra haya seguido en manos de la población nativa, a la persistencia de una fuerte endogamia, y, sobre todo, por la continuidad de un modelo comunitario en el manejo del agua y los acueductos, casas comunales, cementerios y escuelas. Este modelo, mantuvo vigente la cohesión social por la persistencia de prácticas de trabajo colectivo como las mingas, usuales en la construcción y mantenimiento de los acueductos, y aseguró la continuidad de una relativa autonomía en el manejo de los bienes comunitarios por parte de organizaciones como consejos y juntas integrados por habitantes de las comunidades.

Los acueductos rurales en el valle de Atriz, han tenido varias trasformaciones después de 1950; la principal de estas ocurrió durante la década de 1970, con el entubamiento del agua que bajaba a través de las acequias. En Mocondino, el proyecto del nuevo acueducto congregó a los habitantes de este sector, junto con los de Puerres y Canchala. La construcción se hizo a través de mingas, con la participación de todas las familias, quienes debían aportar con días fijos de trabajo para que posteriormente tuvieran derecho a la llave de paso para conectarse a la nueva red. El sistema constó de una bocatoma ubicada en la parte baja de La Toma y una red de tubería para los tres sectores.

Figura 4. Bocatoma del Tambillo

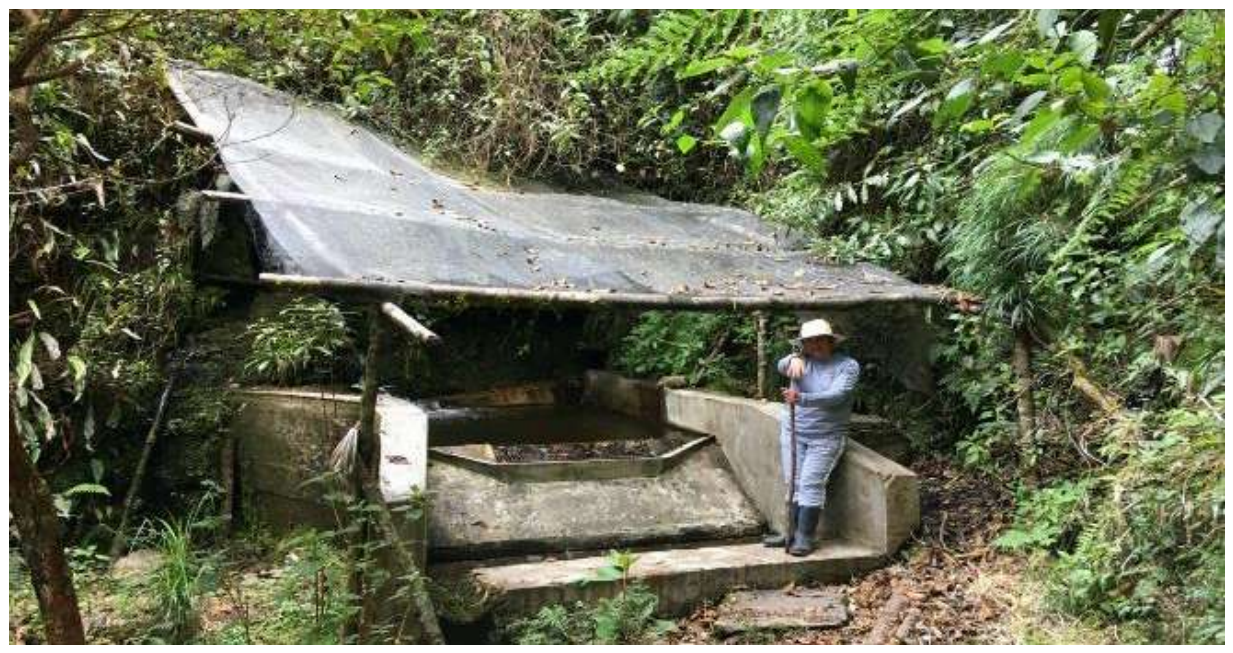

Fuente: presente investigación.

Actualmente, aún suelen organizarse mingas de trabajo para el mantenimiento del sistema, sobre todo cuando ocurren eventos extraordinarios como derrumbes, sin embargo, se paga a un fontanero que realiza reparaciones cotidianas. A pesar de que comparten la misma red de captación y distribución del agua, Mocondino, Puerres y 
Canchala tienen su propia Junta Administradora de Acueducto (de ahora en adelante JAA). Esta es elegida generalmente cada dos años por la asamblea de usuarios, que es la máxima instancia en la toma de decisiones.

Dada su importancia social, los acueductos comunitarios son considerados en Mocondino y en las comunidades rurales del municipio de Pasto, como un patrimonio colectivo heredado de generaciones anteriores. El manejo del agua en estas poblaciones, está relacionado con la apropiación y defensa de los territorios y con la reproducción de identidades comunitarias. Esto se manifiesta, por ejemplo, en los siguientes apartes del manifiesto El agua es una causa de todos de la Red de Acueductos Comunitarios Rurales del Municipio de Pasto (2015):

Las comunidades a través de sus Acueductos Comunitarios supieron y saben asumir la distribución, brindar el servicio, no vendiendo el agua (...) Y desde siempre se rigieron por la ley de la asamblea, y se sostuvieron con las mingas, con la solidaridad comunitaria (...) Con nuestros acueductos comunitarios no se ha generado riqueza económica, sino que hemos construido comunidad, nos hemos esforzado por conservar la biodiversidad y nuestros valores culturales, por fortalecer el sentido de pertenencia, por crear identidad, autonomía y gobernanza.

4.3. ¿Prestadores o abastecedores del agua?: tensiones en torno al funcionamiento de los acueductos comunitarios en Colombia

El uso y la apropiación del agua a través de los acueductos comunitarios, no ha sido ajeno a discusiones y disputas en varios niveles. En Mocondino, por ejemplo, la elección de las últimas JAA ha generado controversias a propósito del manejo del agua, lo que ha enfrentado a un sector conformado mayoritariamente por población que se autoreconoce como indígena, y que es apoyada por el cabildo reconstituido en 2012, y otro sector que no se asume desde una posición étnica vinculado a la Junta de Acción Comunal. Este último grupo, el cual es mayoritario, ha acusado a los indígenas de querer apropiarse del agua, amparándose en la legislación colombiana que da ciertas garantías en el manejo y control de los territorios a las poblaciones étnicas, mientras que el cabildo ha denunciado la complicidad de la junta, en la entrega de nuevas llaves a urbanizadores y personas ajenas a la comunidad, así como la falta de interés en la defensa del territorio.

Por otro lado, la autonomía de cada junta para el caso de Mocondino, Puerres y Canchala, no ha evitado que existan discusiones originadas por discrepancias en el manejo del sistema, la repartición de caudales para cada comunidad y la entrega de llaves a nuevos usuarios. Este último, es un asunto delicado ya que las comunidades y sus juntas, procuran que los nuevos usuarios pertenezcan al pueblo y son cuidadosos de que el agua no sea utilizada de manera indiscriminada, para usos industriales o cultivos extensivos. Así, los derechos para el acceso al agua están definidos por usos y costumbres, que, entre otras cosas, condicionan este acceso al trabajo en la construcción y el mantenimiento de la infraestructura hidráulica, hecho que en ocasiones es motivo de desencuentro con los foráneos, que llegan a estas comunidades y están acostumbrados a obtener el agua sólo a cambio de un pago periódico.

Otra de las discusiones en relación con el manejo del agua, está relacionada con la regulación del Estado colombiano sobre los sistemas comunitarios para el abastecimiento del agua en Colombia y la oposición de estos a dichas medidas. En Colombia, existen alrededor de doce mil acueductos comunitarios, ubicados en su mayoría en áreas rurales y en menor medida en áreas suburbanas. Al igual que en el caso del municipio de Pasto, 
estos acueductos han surgido como iniciativas de autogestión para el acceso al agua por parte de poblaciones que han migrado del campo a la ciudad, o de poblaciones cuyos territorios han sido impactados por fenómenos de expansión urbana (Correa, 2010; Moncada, Pérez y Valencia, 2013; Montoya, 2017).

Bajo este telón de fondo y en el caso específico del municipio de Pasto, los acueductos comunitarios han denunciado desde hace varios años continuas presiones por parte de las institucionales municipales para su transformación empresarial. Según la alcaldía, lo que se pretende con esto es cumplir con las normas contempladas por la Comisión de Regulación del Agua (CRA) y la Superintendencia de Servicios Públicos, entidades creadas mediante la Ley 142 o Ley de servicios públicos. Además, se considera que estas organizaciones comunitarias "cobran muy poco por el agua", son inconscientes respecto al despilfarro y la escasez de agua por no contar con la micromedición, no proveen agua de calidad debido a la deficiencia de sus sistemas de potabilización y cuentan con malas prácticas de administración, entre otras razones porque su personal no está capacitado académica ni técnicamente (Secretaria de Gestión Ambiental Rural de la alcaldía de Pasto, comunicación personal, abril de 2019).

Esto ha generado un pulso entre las instituciones municipales y regionales y los acueductos comunitarios, que desde 2014, decidieron conformar una red municipal y enlazarse a la Red Nacional de Acueductos Comunitarios, organización que propende por la defensa del modelo comunitario para el manejo del agua y busca que este sea reconocido por el Estado, ya que considera que las normas que regulan la prestación del servicio del agua en Colombia favorece solo a las empresas públicas, privadas o mixtas que prestan este servicio.

La tensión en el modelo para el manejo del agua, se ha sumado a las disputas que se señalaban a propósito de la distribución y apropiación del líquido en algunos sectores del municipio de Pasto. A continuación, se expondrá un caso en particular que ha tenido lugar en el sector suroriental y que, nuevamente como hace más de ochenta años, ha involucrado a los habitantes de Mocondino, Puerres y Canchala.

\subsection{Un "acueducto paralelo" en Mocondino}

En 2011, un grupo de familias foráneas de Mocondino adquirieron y parcelaron un predio de la vereda Canchala, catalogado como suelo rural según la alcaldía de Pasto y por tanto inhabilitado para este tipo de fraccionamientos. Estas familias solicitaron a la JAA de la vereda, la conexión a la red del acueducto comunitario, sin embargo, la junta se opuso argumentando que este tipo de proyectos no se ajustaban a los estatutos internos, además que el crecimiento en el número de usuarios perjudicaría toda la comunidad, debido a la falta de agua que se presentaba en el sector. Ante esta negativa, las familias que se fueron asentando en el predio parcelado conformaron la vereda Alto Canchala y mediante una acción popular, comprometieron a la alcaldía de Pasto para la construcción de un acueducto independiente.

Los habitantes de Mocondino se opusieron a este proyecto, argumentando que el agua entregada para el nuevo acueducto, proveniente de La Toma, ya estaba concesionada por un grupo de familias que subsistían de la agricultura y la ganadería, además señalaron que el agua era utilizada por el acueducto de Mocondino, Puerres y Canchala en temporada seca. 
Las JAA de Mocondino, Puerres y Canchala fueron denunciadas por representantes de la vereda Alto Canchala ante un despacho judicial de Pasto, que acogió su argumento, que al ser un derecho fundamental el abastecimiento del agua, no podía ser negado ni obstaculizado. Sin embargo, la comunidad y las juntas de los, tres sectores, siguieron oponiéndose a conectar a la red a los demandantes, argumentando no contar con las condiciones de infraestructura necesarias para garantizar este abastecimiento, y también, insistiendo en que el loteo y la urbanización del sector rural ponía en riesgo el suministro de agua para la población local, debido a la disminución de los caudales por la sobre explotación de concesiones.

Este conflicto estuvo presente en los juzgados por varios años, al cabo de los cuales la alcaldía de Pasto, obligada a cumplir con el fallo judicial, debió buscar otra opción para abastecer de agua a la urbanización que pretendía construirse en Alto Canchala. A finales del 2018, optó por la construcción de un tanque de almacenamiento al que la empresa de acueducto de la ciudad, bombeara agua desde su red para venderla a la urbanización a partir de 2020.

Pese a la aparente solución del conflicto, los habitantes de Mocondino continúan en alerta. En varias oportunidades han denunciado nuevos loteos en la zona baja del corregimiento para la creación de nuevas urbanizaciones, donde los recién llegados, en general, familias vulnerables quienes se asientan en los perímetros de la ciudad debido al bajo costo de la tierra y los servicios, han recurrido a la misma estrategia ejemplificada para el caso de Alto Canchala, es decir, parcelar y construir viviendas aprovechando la falta de control de las autoridades municipales, y luego, ante la negativa y oposición de las JAA y las comunidades, obteniendo amparos judiciales para ser conectados a la red de acueducto.

Figura 5. Panorámica de Pasto desde el sector de Mocondino bajo

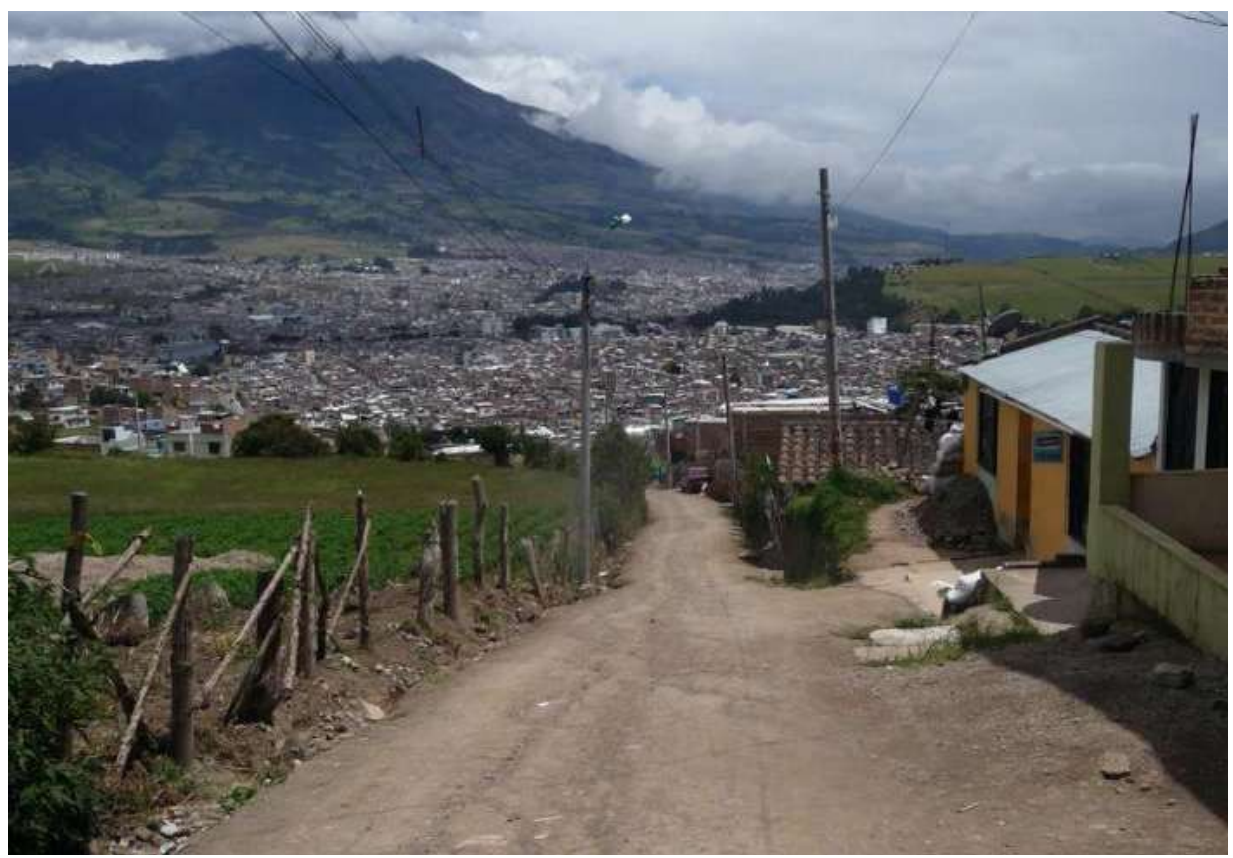

Fuente: presente investigación. 
Bajo este panorama, los conflictos por el acceso uso y apropiación del agua en el sector suroriental del valle de Atriz, continúan latentes y posiblemente aumentarán hacia futuro. La construcción de la vía perimetral de Pasto, que atravesó a Mocondino y otros pueblos de la parte alta del valle de Atriz, obra que hace parte del Corredor Intermodal Tumaco - Belém do Pará, entre Colombia y Brasil, aumentó los intereses comerciales e industriales de terrenos aledaños a la vía, lo que llevará seguramente a un aumento en la solicitud de nuevas concesiones de agua, en la microcuenca del río Dolores.

Por otra parte, los intereses de diferentes actores sobre las áreas rurales del municipio de Pasto y sus recursos, principalmente el agua, de lo cual es un reflejo la pretensión de los gremios económicos de convertir estos lugares en "polos de desarrollo" y epicentros del crecimiento urbano, industrial y comercial de la ciudad, se suma a las acciones y políticas impulsadas por las autoridades municipales, dirigidas a asegurar el control de los bosques y cuencas altas de los ríos del valle de Atriz y de regiones circundantes, con el fin de asegurar el abastecimiento de agua para Pasto y la disponibilidad del líquido para las iniciativas de carácter público y privado, que se pretenden llevar a cabo hacia futuro en las áreas de expansión de la ciudad.

Estos intereses, así como las narrativas e imaginarios en que se sostienen, no son recientes. Desde una mirada de larga duración, se aprecian elementos que se repiten y que son los hilos conductores que tejen los dos momentos abordados en este artículo. Uno es la idea que ha prevalecido entre las élites locales, de considerar los espacios ubicados fuera de la ciudad, como "baldíos", susceptibles de ser ocupados y despojados a quienes allí han habitado, con la finalidad de desarrollar procesos de acumulación de capital, en un momento a través de la agricultura y de la ganadería extensiva, y desde hace unas décadas, mediante el desarrollo de proyectos urbanísticos y comerciales, pero también, con el fin de ubicar en estos espacios todos los usos del suelo indeseables en la ciudad.

Y la otra narrativa, atravesada por el racismo estructural que ha marcado históricamente la relación entre los habitantes de la parte alta del valle de Atriz y quienes viven en Pasto, es la de considerar a quienes habitan en los entornos rurales, como incapaces para la administración, ordenamiento y planificación de sus recursos y territorios, como por ejemplo, el agua a través de sus acueductos, y además como principales responsables de la degradación ambiental de los bosques y cuencas que abastecen a la ciudad. ${ }^{4}$

\section{Discusión y conclusiones}

Estas discusiones evidencian cómo en el municipio de Pasto, la tierra y el agua han sido elementos centrales en la definición de las relaciones de quienes allí habitan, y donde el favorecimiento de algunos sectores, primordialmente de aquellos que viven en la ciudad, mestizos herederos de las prácticas coloniales españolas, ha significado el perjuicio de quienes han sido empujados y desarraigados de sus tierras de origen, descendientes de los pobladores nativos, que habitaban la región antes de la llegada de los españoles. Sin embargo, es cierto también, que las ideas y prácticas modernizantes que conciben el agua

\footnotetext{
${ }^{4}$ Actualmente, esta visión mercantil sobre la tierra se enfrenta con acciones por parte de sectores rurales del municipio, que propenden por la defensa de la autonomía territorial. Masagualli y Lagares (2017) muestran la relación entre autonomía y territorio en otro contexto de los Andes colombianos.
} 
y la tierra, y en general, la naturaleza, como ámbitos separados de la sociedad y la cultura, y por ende, como recursos susceptibles de ser apropiados, controlados y manipulados, han calado hondamente en los imaginarios de quienes habitan en los entornos rurales del municipio, generando tensiones por la trasformación de los significados en torno al agua y a los sistemas e instituciones establecidos para su manejo.

Los intereses por el acceso, uso y distribución del agua han generado a lo largo del tiempo, conflictos permanentes los cuales se retrataron a través de dos momentos, los cuales deben entenderse bajo el telón de fondo de las políticas estatales en relación con el agua, su correspondencia con el contexto global y su impacto a nivel local. El primer momento analizado, anterior a la mitad del siglo XX, el cual cabe en lo que en otros trabajos se ha denominado como período de municipalización (López, 2016; Moncada etal., 2013; Swyngedouw, 2005), en el cual la prestación del servicio de agua es vista como un asunto de utilidad pública que debe ser provisto por el Estado, implicó para el valle de Atriz características singulares, como que el naciente proyecto de acueducto, se proyectará solo para algunos sectores de la ciudad o que los pobladores de la parte alta, fueran perturbados permanentemente para hacer uso del agua que nacía en sus territorios.

El análisis del segundo momento, relacionado a la última década, no puede desligarse igualmente del contexto nacional, así como de los procesos de mercantilización de la naturaleza, en general y el agua, en particular. Si bien este período ha estado caracterizado por políticas de apertura económica, y la llegada de empresas e intereses privados para competir por la prestación del servicio del agua, también ha existido un incremento de la regulación del Estado en este sector. Esto se ha materializado como se mostró, en la creación de entidades reguladoras, así como de políticas que han afectado y amenazado la existencia de los sistemas comunitarios para el manejo del agua. Lo anterior, refuerza lo que ya han sugerido otros autores (Swyngedouw, 2005), a propósito del riesgo de lecturas que generalizan los efectos del neoliberalismo en sectores concretos como el del agua, ya que, en este caso, lejos de estar al margen, el Estado ha jugado un papel esencial promoviendo políticas y normas de regulación respecto al uso y manejo del líquido y abriendo el camino a una participación cada vez más amplia del sector privado.

Estos dos momentos ejemplifican la complejidad de factores involucrados alrededor del manejo, uso y apropiación del agua en el municipio de Pasto, así como la relación entre el agua, territorio y poder; proponiendo que esta relación podía ser analizada a partir del concepto de territorio hidrosocial, desde donde se plantea que la apropiación y la significación del territorio se entrecruza de manera permanente con las formas de uso y manejo del agua, por lo que las disputas por estos elementos no pueden verse de manera separada. En el municipio de Pasto, han coexistido de manera relacional y conflictiva diversas formas de uso y apropiación del territorio, las cuales, por una parte, se han trasformado en el tiempo, y, por otra, casi nunca se circunscriben ni limitan a lo que podría caracterizarse como el espacio rural o urbano. Estas formas de apropiación del territorio, se expresan a su vez en una diversidad de prácticas en el uso y manejo del agua y de significados en torno a este elemento, también en constante discusión. 
$\mathbf{8 8}$ Procesos de configuración territorial y conflictos por el agua en el Municipio de Pasto, Colombia

Así, "los territorios hidrosociales (imaginados, planificados o materializados) presentan funciones, valores y significados en disputa, en tanto definen los procesos de inclusión y exclusión, desarrollo y marginalización, así como la distribución de los beneficios y perjuicios que afectan a distintos grupos de formas diferentes" (Boelens et al, 2016, p.2). Y en el municipio de Pasto, donde en las últimas décadas ha existido un aumento de intereses y tensiones en torno al acceso agua, particularmente a causa del crecimiento urbano sobre los corregimientos y veredas, las preguntas sobre ¿quién se beneficia?, ¿a quién se perjudica?, y ¿de qué modo?, cobran aún más sentido. Como señala- Swyngedouw (1997), la conquista ecológica del agua ha sido un componente necesario para la expansión y crecimiento de la ciudad, lo que ha resultado en procesos profundamente exclusivos y marginales que definen el acceso y/o exclusión del agua por parte de determinados sectores sociales. Además, como un proceso a la vez político-económico y ecológico, el fenómeno de la urbanización vincula lugares y ecosistemas distantes, donde los actantes "no humanos", como el agua y su flujo, juegan un rol activo (Heynen etal., 2006).

Sin embargo, coincidiendo con Radonic y Kelly-Richards (2015), para el caso mexicano de Hermosillo y Nogales, desde su propuesta de alternativas infraestructurales, y con Marcela López (2005), con su idea de desmercantilización del agua como estrategia por parte de sectores populares en Medellín, los trabajos de ecología política han sido relativamente incapaces de adentrarse en detalle, a indagar por las formas de manejo del agua por parte de sectores sociales históricamente marginalizados en contextos urbanos. En este sentido, es necesario comprender qué sucede en los márgenes de estos contextos, es decir, comprender las prácticas y discursos cotidianos de sectores que habitan en las periferias de las ciudades y que históricamente han resultado desfavorecidos y privados del acceso al agua. En concordancia con las autoras, aquí la infraestructura puede ser un objeto etnográfico fértil, para ver la interrelación entre la materialidad y los significados producidos en torno al agua y la reproducción de desigualdades sociales a través de las disputas por el líquido.

Para el caso del municipio de Pasto, los habitantes de los barrios periféricos y los de la parte alta del valle de Atriz, han jugado un papel activo en la construcción y mantenimiento de infraestructuras y la creación de organizaciones, con el fin de acceder y manejar el agua de acuerdo a sus propios criterios, y han adelantado acciones de diversa índole cuando estos sistemas han sido vulnerados. En la investigación, se observó especialmente el acueducto de Mocondino, Puerres y Canchala. Allí, como en los demás pueblos de la parte alta del valle de Atriz y de otras poblaciones rurales y suburbanas de los Andes colombianos, el manejo del agua, principalmente para su uso y consumo doméstico, ha motivado históricamente procesos de organización social, así como la construcción y mantenimiento de una infraestructura, donde se han fundido imaginarios en relación con el agua en particular y con la naturaleza en general.

Sobre ¿qué tanto los acueductos comunitarios representan una alternativa frente a la visión hegemónica neoliberal?, es una interrogante que merece atención y que tiene muchos bemoles. De nuevo, coincidiendo con Radonic y Kelly-Richards (2015), no es el propósito romantizar este tipo de sistemas, entre otras razones porque en el manejo que se le da al agua en estos lugares se reproducen relaciones de poder, atravesadas por el género 
y la etnicidad, así como tampoco se pueden obviar las ambiguas relaciones que las organizaciones comunitarias que administran el agua han mantenido con el Estado, muchas veces bajo redes clientelares, y tampoco puede pensarse que son sistemas estáticos sin considerar el carácter dinámico y fluido de las normas construidas para la regulación de derechos en torno al agua en estos lugares (Boelens, Roth, y Zwarteveen, 2004).

Sin embargo, también se considera, desde la cercanía afectiva y política que ha vinculado al autor de este trabajo con los procesos sociales y políticos de las poblaciones rurales del valle de Atriz, que la infraestructura y las prácticas de gestión, como instituciones y normas, construidas, preservadas y mantenidas colectivamente para el manejo del agua, ofrecen pistas e indicios para entender su complejidad social y cultural, la relación con sus territorios y para comprender por qué a pesar de los embates que han sobrellevado y el despojo al que han sido sometidos persisten aún como sociedades.

El ¿qué tanto? y de ¿qué forma? se le da cabida a esto, tiene hondas implicaciones en cualquier ejercicio académico, no solo antropológico, que aunque supone no desconocer las relaciones de poder que se generan en los mundos locales que se estudian y donde se tejen vínculos y afectos emocionales de solidaridad, también implica ser conscientes de que, en un nivel más amplio, estos mundos y sus actores por lo general son los perdedores en la lucha por el acceso y la distribución de los recursos, ya que sus márgenes de maniobra son siempre más limitados.

\section{Referencias bibliográficas}

Acueductos Comunitarios Rurales del Municipio de Pasto. (2015). El agua es una causa de todos. Manuscrito no publicado.

Álvarez, M. T. (2012). Pasto y sus intentos modernizadores en el período de la República Liberal (1930-1946). Historia y Memoria, (5), 201-223.

Masagualli, N., y Lagares, O. (2017). Alternativas del poder político en los movimientos sociales-rurales de Colombia: caso organización indígena del norte del Cauca. Collectivus, Revista de Ciencias Sociales, 4(2), 36-54. DOI https://doi.org/10.15648/Coll.2. 2017.3

Boelens, R., Roth, D., \& Zwarteveen, M. (2004). Pluralismo legal, derechos locales y gestión del agua: entre el reconocimiento analítico y la estrategia política. En F. Peña (Ed.), Los pueblos indígenas y el agua: desafios del S XIX (pp. 161-194). México: El Colegio de San Luis/WALIR/IMTA/.

Boelens, Rutgerd, Jaime Hoogesteger, Erik Swyngedouw, Jeroen Vos, y Philippus Wester. (2017). Territorios hidrosociales: una perspectiva desde la ecología política. En C. Salamanca y F. Astudillo (Eds.), Recursos, vínculos y territorios. Inflexiones transversales en torno al agua (pp. 85-104). Argentina: Universidad Nacional de Rosario.

Correa, H. D. (2010). Acueductos Comunitarios, patrimonio público y movimientos sociales. En H. Vélez (Ed.), Justicia hídrica. 7 ensayos como aportes para articular las luchas (pp. 81-106). Bogotá: CENSAT AGUA VIVA. 
Heynen, N., Kaika, M., \& Swyngedouw, E. (2006). Urban political ecology: politicizing the production of urban natures. En N. Heynen, M. Kaika, \& E. Swyngedouw (Eds.), In the Nature of Cities. Urban political ecology and the politics of urban metabolism (pp. 1-19). London: Routledge.

López, M. (2016). Paisajes hídricos urbanos en disputa: Agua, poder y fragmentación urbana en Medellín, Colombia. Medellín: CONFIAR, Penca de Sábila, SINPRO.

Carla Beatriz Zamora LomelíMoncada, J., Pérez, C., \& Valencia, G. D. V. (2013). Comunidades organizadas y el servicio público de agua potable en Colombia: una defensa de la tercera opción económica desde la teoría de recursos de uso común. Ecos de Economía, $17(37), 125-159$.

Montoya, E. (2017). Los acueductos y sistemas de distribución de agua comunitarios en el área rural de Bogotá y la gobernanza del agua en la ciudad. Universidad Nacional de Colombia, Bogotá.

Perugache, J. A. (2017). Voltear la tierra para despertar la vida. El resurgimiento de los pueblos del Valle de Atriz, en el municipio de Pasto. Maguaré, 31(1), 153-191.

Quintana, A. P. (2008). El conflicto por la gestión del servicio de acueducto en Dosquebradas (Risaralda-Colombia). Un estudio desde la ecología política (tesis de doctorado). Universidad de Barcelona, Barcelona, España.

Radonic, L. \& Kelly-Richards, S. (2015). Pipes and praxis: a methodological contribution to the urban political ecology of water. Journal of Political Ecology, 22, 389-409.

Suarez, N. (2020). Recuperación crítica y devolución sistemática del retorno a la tierra de Orlando Fals Borda. Collectivus, Revista De Ciencias Sociales, 7(1), 13-36. DOI: https://doi.org/10.15648/Collectivus.vol7num1.2020.2528

Velasco, J., y Puerres, L. (24 de enero de 1941). Proceso promovido por Carmela de la Rosa y su esposo Luis E. Gavilanes contra los cabildos de Mocondino, Puerres y Canchala. Fondo Cabildo de Pasto, caja 358, libro 1. Archivo Histórico de Pasto. 